TITLE:

\title{
Male replacement and stability of territorial boundary in a group of agile gibbons (Hylobates agilis agilis) in West Sumatra, Indonesia.
}

$\operatorname{AUTHOR}(S)$ :

Koda, Hiroki; Oyakawa, Chisako; Nurulkamilah, Santi; Rizaldi; Sugiura, Hideki; Bakar, Amsir; Masataka, Nobuo

\section{CITATION:}

Koda, Hiroki ... [et al]. Male replacement and stability of territorial boundary in a group of agile gibbons (Hylobates agilis agilis) in West Sumatra, Indonesia.. Primates 2012, 53(4): 327-332

ISSUE DATE:

2012-10

URL:

http://hdl.handle.net/2433/160375

\section{RIGHT:}

The final publication is available at www.springerlink.com; この論文は 著者最終稿です。内容が印刷版と異なることがありますので、引用の 際には出版社版をご確認ご利用ください。This is the Accepted Author Manuscript. Please cite only the published version. 


\section{Male Replacement and Stability of Territorial Boundary in a Group of Agile Gibbons (Hylobates agilis agilis) in West Sumatra, Indonesia}

Hiroki Koda $^{1 *}$, Chisako Oyakawa ${ }^{1}$, Santi Nurulkamilah ${ }^{2}$, Rizaldi ${ }^{1,2}$, Hideki Sugiura ${ }^{1}$, Amsir Bakar², and Nobuo Masataka ${ }^{1}$

${ }^{1}$ Primate Research Institute, Kyoto University, Japan

${ }^{2}$ Department of Biology, Andalas University, Indonesia

*Author for correspondence: Hiroki Koda, Primate Research Institute, Kyoto University, Kanrin 41, Inuyama, Aichi 484-8506, Japan

E-mail: koda.hiroki.7a@kyoto-u.ac.jp

Koda H., Oyakawa C., Nurulkamilah S., Rizaldi, Sugiura H., Bakar A., Masataka N.. Male replacement and stability of territorial boundary in a group of agile gibbons (Hylobates agilis agilis) in West Sumatra, Indonesia. Primates. 53(4), 327-332 (2012) 
Koda et al. Male replacement and home range stability of agile gibbons/2

\section{Abstract}

We report membership change in a group of wild agile gibbons, Hylobates agilis agilis, in West Sumatra, Indonesia. During 6-month observational periods, we focused on a particular unit of individuals known as the B group. We confirmed that the group consisted of five individuals: one adult female, one adult male, one subadult male, one subadult female, and one infant male. During our observations, the resident adult male and the two subadult individuals dispersed or disappeared, and a new adult male took over the group. We examined the effects of the male replacement on the territorial boundary, using the auditory census technique. The boundary was stable. We also documented the succession of the home range. Our results indicate a flexible social structure in this species and contribute some useful data to an ongoing debate on their social dynamics.

Key words: Hylobates agilis agilis; male replacements; auditory census; home range estimation; pair formation 
Koda et al. Male replacement and home range stability of agile gibbons/3

\section{INTRODUCTION}

Gibbons are distributed throughout the tropical rain forests of Southeast Asia and form monogamous and territorial family groups. The current classification system recognizes 14 species (for discussions, see Groves 2001). Their specializations include a type of locomotion that is usually referred to as brachiation. They are able to not only walk on branches but also to move swiftly below branches, making them more efficient foragers than other mammals of comparable body weight in the thin-branch niche of trees. Their groups usually consist of one adult pair and one to three dependent immature individuals. These groups live in exclusive territories that they actively defend. Another well-known specialization is their loud morning vocalizations. All gibbon species produce stereotyped patterns of vocalizations that are often referred to as 'songs' (for review, see Geissmann 2002). In most species, mated pairs combine their songs in a relatively rigid pattern to produce a coordinated 'duet.' The songs and duets may maintain spatial organization among neighboring family groups and advertise territory to non-mate conspecifics to deter them from intruding upon an occupied territory (Whitten 1982a; Haimoff 1984). The presumed use of the duet songs to advertise territories and strengthen pair bonds is consistent with studies on songbirds (e.g., Farabaugh 1982). These and other early reports suggest that gibbons have a stable, monogamous social structure, with individuals living in nuclear family groups (e.g., Leighton 1987).

However, a large body of evidence that contradicts this traditional view has developed in the past decade. Palombit (1994a, b) was the first to challenge the nuclear family model in hylobatids. He summarized a 6-year history of group changes in 
Koda et al. Male replacement and home range stability of agile gibbons/4

white-handed gibbons, Hylobates lar, and siamang, Symphalangus syndactylus, at Ketambe Research Station, Sumatra. Mate desertion and re-pairing were surprisingly frequent in all six groups studied, and gave rise to groups that were not nuclear families. He concluded that "the complexities of social life in these animals extend beyond the narrow limits established by a rigid nuclear family concept.” Subsequently, Brockelman et al. (1998) reported demography data from wild white-handed gibbon groups in Khao Yai National Park, central Thailand, based on 18 years of longitudinal observations. They reported two cases in which the resident male in a group was replaced by a dispersing adult from a neighboring group. In one case, forcible displacement of the resident male resulted in a group that included a young juvenile, presumably fathered by the previous male; two younger juveniles (probably brothers) from the new male's original group; and (later) offspring of the new pair. Nevertheless, social relationships within this heterogeneous group appeared harmonious. Other works have also suggested the possibility of a flexible social structure (Reichard 1995; Fuentes 2000; Sommer and Reichard 2000; Bartlett 2003; Lappan 2007; Barelli et al. 2008). All of these findings challenge the traditional view of the gibbon social system (Sommer and Reichard 2000).

We report a change of membership in a group of wild agile gibbons, Hylobates agilis agilis, in West Sumatra. This species has rarely been investigated. We observed the replacement of the resident male of one group (“B group”) by an adult male from outside the B group’s home range. We also examined the effect of mate replacement on territorial boundaries using the auditory census technique.

\section{METHODS}


Koda et al. Male replacement and home range stability of agile gibbons/5

We investigated a population of wild agile gibbons in a research area of tropical rain forest owned by Andalas University in Limau Manis, Padang ( $0^{\circ} 54^{\prime} \mathrm{S}$, $100^{\circ} 28^{\prime} \mathrm{E}$ ), West Sumatra, Indonesia. The site is a mixture of primary and secondary forest. The study took place from 12 September to 31 November 2005 (the first observational period) and 12 July to 8 September 2006 (the second observational period). The average annual temperature in Padang is $26.1^{\circ} \mathrm{C}$, and the annual rainfall is $6000 \mathrm{~mm}$. Our previous investigation identified more than seven gibbon groups inhabiting the study area, and their approximate home ranges were estimated by both auditory census and direct observation (Oyakawa et al. 2007). In the present report, we focused on theBgroup because we were able to evaluate its membership during both study periods. The adult female and her offspring were well-habituated to human observers, while other members (for detailed membership, see "Results” section) were not perfectly habituated. Furthermore, we attempted to estimate their home range more objectively than our preliminary estimation of the home range for the B group (Oyakawa et al. 2007). The home range of the group was located at the center of our research site.

We estimated their home range based on both direct observation and their songs, which were loud enough to be heard approximately $1 \mathrm{~km}$ away from the singing location. Indeed, the direct observation was strong confirmation of the places that the gibbons used, but it would sometimes be difficult to follow the subject gibbon family during an entire day. Given that they regularly sing their loud duets, auditory estimations would be a powerful way to confirm their location. Gibbons sing more intensively in the early morning, and a single behavioral episode typically lasts about 30 min. Two or three researchers walked along forest trails and listened for the gibbon 
Koda et al. Male replacement and home range stability of agile gibbons/6

songs. When observers heard a song, they recorded the time; their own location, using a global positioning system (GPS; Empex Map21Ex, Tokyo, Japan); and the direction of the song, using a magnetic compass. To determine the precise location of a singing gibbon, two observers in radio contact measured song direction relative to their own locations. Their directional lines were drawn on a map, and the point of intersection was considered the singing location. The map with all of the estimated gibbon locations was digitized using geographic information system software (ArcGIS ver 9.0; ESRI, Redlands, CA, USA).

The home ranges were estimated using the minimum convex polygon (MCP) method with the location data based only on singing. For the direct observation data, the number of observations in 2005 and 2006 were different; we counted 13 events of direct observation for a total of $7 \mathrm{~h}$ in 2005, and 63 events of direct observation for a total of $31 \mathrm{~h}$ in 2006. This great difference in direct observation opportunities is related to the human observers' skills in this field. At the time when we started this gibbon project, around 2005, the human observers were not used to following the animals in their steep landscape even though the animals were habituated to humans, but in 2006 our skills had improved and we were able to follow them for a relatively longer time. On the other hand, the observation numbers derived from the auditory census data were not so different between 2005 and 2006 (see “Results” section). We could easily identify the gibbons by songs even if we could not see them. Particularly, the Bgroup was extremely easy to identify, because the adult female of this group showed identical acoustic features in her great calls. We found sudden frequency modulations and hoarse pitch in the maximum frequency of her great calls (see Fig. 1). Also, the B group often sing their duets in the morning, as do the other gibbons. Therefore, we could regularly record their 
songs and duets in the morning.

To avoid the methodological bias of different numbers of direct observation times in 2005 and 2006, we used only the auditory census data for home range estimation. The MCP method draws the smallest convex polygon that contains any given percentage of location points (e.g., White and Garrott 1990). We estimated the home range as the polygon that contained $100 \%$ of the points, using the Animal Movement 2.0 extension program for ArcGIS (Hooge and Eichenlaub 1997). The range was estimated separately for each study period. To examine home range flexibility/stability, we compared the estimated home ranges in the two periods and calculated their overlap. Furthermore, we calculated the centers of gravity of the estimated polygons for degrees of geographical center of the home ranges, and examined the changes in their centers of gravity. Here, the center of gravity of polygons was mathematically defined as the intersection point of all straight lines that divided the polygon into two parts of equal moment about the lines, and was automatically computed by ArcGIS (Fig. 2).

The research adhered to the legal requirements of Indonesia.

\section{RESULTS}

Our observations confirmed that the membership of the B group had changed. In the first observational period, we identified five gibbons: one adult female (named Gula), one adult male (Laki-laki), one subadult male (Malam), one subadult female (Bunga), and one infant male (Air). Based on their organized duets, Gula and Laki-laki were presumed to be the group's mating pair. However, in the second observational 
Koda et al. Male replacement and home range stability of agile gibbons/8

period, we identified three gibbons: Gula, Air, and a new adult male, Garam. Gula and Air were positively identified in both periods because this mother-infant pair possesses bright buff-colored fur, and the agile gibbon is usually a deeper shade of brown (Marshall and Sugardjito 1986). The fur colors of Laki-laki, Malam, and Garam were light brown, black, and dark brown, respectively. Although differentiating between Malam and Garam was difficult, we were certain that the pair male had been replaced by Garam (i.e., that we were not confusing Garam with Malam), based not only on fur color but also on body size. Garam was substantially larger than Malam, indicating that the former was a mature adult and the latter a subadult or adolescent male. Interestingly, at the time of our observation in 2006, Gula and Garam always sang duets together, suggesting that Garam’s replacement and taking-over of the B group had been successfully achieved in terms of pair-bonding strength.

Regarding the home range estimates of the B group, 29 (1.16/day average) and 49 (2.04/day average) singing location points were recorded during the first and second observational periods, respectively. Applying the MCP method, the home ranges were calculated to be 11.47 and 12.10 ha for the two periods, respectively. The ranges overlapped by 9.10 ha, which was $79.3 \%$ of the 2005 home range (Fig. 2). The change in the center of gravity was $43.8 \mathrm{~m}$.

\section{DISCUSSION}

Here, we examined the influence of social structure dynamics on the home range of a group of wild agile gibbons by conducting an auditory census. Generally, investigations of the home ranges of primates and other animals rely on direct 
Koda et al. Male replacement and home range stability of agile gibbons/9

observation or on location measurement by GPS attached to a subject animal, but our present data were based on the auditory information of the animals' singing. We cannot deny underestimations of their home ranges both for 2005 and for 2006. However, we believe our analysis is still effective for home range comparisons, because we used only location data derived from their singing to avoid sampling bias.

Our observations are consistent with recent findings that suggest a flexible and dynamic social structure in gibbons (Palombit 1994a; Brockelman et al. 1998; Sommer and Reichard 2000; Lappan 2007; Reichard and Barelli 2008). Moreover, and of particular interest, we found that the territorial boundary remained stable even after mate replacement had occurred and the new mated pair had taken over the territory.

Very few studies have examined the effects of membership change in gibbon groups on their territory. The Observations similar to ours were reported in early studies of white-handed gibbons and siamangs at Kuala Lompat in the Malay peninsula (MacKinnon and MacKinnon 1977) and in studies of Kloss gibbons on Siberut Island, Indonesia (Whitten 1982b). Both of these studies suggested the permanence of the territory of gibbon families. After these pioneer observations, Brockelman et al. (1998) first reported the influence of social dynamics on their territorial boundary in white-handed gibbons, based on longitudinal observations. They reported that territory size changed when a pair-mate male was replaced. At the time of the replacement, severe wounding was observed in the pair male of the neighboring group. The replaced male no longer regularly duetted with his previous mate, had difficulty in keeping up with the group, and ultimately disappeared. Later, three male offspring of the newly mated pair attempted to replace an adult male living in a group adjacent to their own. One of the three succeeded, and forcibly took over the group; the other two males 
Koda et al. Male replacement and home range stability of agile gibbons/10

dispersed and organized new groups in adjacent areas. Despite these changes in the group’s organization, the territorial boundary was virtually unaffected. The territorial boundary between this group and the neighboring group was changed to $150 \mathrm{~m}$ from previous measurement, and the area of their territory changed from 26 to 20 ha after the replacements. Given the change of the territorial boundary reported by Brockelman et al. (1998), our results showing $79 \%$ overlapping and a 44-m change in the territory center seem to be consistent with their report of white-handed gibbons, in terms of territorial stability. Their result may have been related to the high population density at their study site, similar to that of the wild agile gibbons in our research area. Our observations also seem to show a phenomenon quite similar to that reported by (MacKinnon and MacKinnon 1977) in their pioneer observations of white-handed gibbons. In 2006, the new male in our group, Garam, frequently made duets together with Gula, suggesting their stable formation as a new pair. We have continued to investigate the composition of the B group at least once a year since 2004. After the male replacement between 2005 and 2006, Garam and Gula maintained the B group at least until 2009. Gula delivered a new male baby in 2007, who would have been the son of Garam (Koda et al., unpublished data). All these observations suggested that Garam had successfully taken over the B group, similar to the reported replacements in white-handed gibbons. It is unclear from our observations why three animals disappeared from the B group. However, it is unlikely that all three were forced to desert the group at the same time. Palombit (1994a, b) reported that mate changes in whitehanded gibbons and siamangs were the result of death or unforced desertion. This phenomenon may also be common in agile gibbons. Moreover, we estimated a high group density in our study area (approximately 8 groups per $1 \mathrm{~km} 2$; Koda et al., unpublished data), which suggests that 
Koda et al. Male replacement and home range stability of agile gibbons/11

space for the formation of new groups is restricted and that territorial changes may not be feasible. Our findings suggest that, under such circumstances, the territory defended by the previously mated pair could be assumed by a new pair. Why territorial succession is possible in gibbons is an interesting question for future study.

Our observations in agile gibbons contribute some useful data to an ongoing debate on their social dynamics, particularly regarding possible infanticide in gibbon species (for discussions, see van Schaik and Dunbar 1990; Palombit 1999; Brockelman 2009). If male replacements are commonly observed in gibbons, then, theoretically, possible risks of infanticide could be assumed, because their social systems are basically monogamous. After the male replacement, the new male would not be the father of the original offspring, resulting in increasing risks of infanticide. Otherwise, it is possible that female gibbons could have evolved a counter-strategy such as extra-pair copulation to confuse the paternity. Interestingly, extra-pair copulations have been reported in white-handed gibbons (Reichard 1995) and in siamangs (Palombit 1994b). We have not yet observed direct evidence for extra-pair copulation in agile gibbons, but we observed an interesting anecdotal episode suggesting extra-pair copulation. In February 2005, we observed extra-pair duetting between Gula and the adult male of the neighboring group, named group A (H. Koda, personal observation). First, the adult male of group A solely sang his songs around the territorial boundary between groups A and B. Then Gula approached that male, and finally sang her great call several times. The male of group A perfectly replied to Gula's great calls. Interestingly, just after the extra-pair duettings, Laki-laki ran to approach Gula, and immediately started to sing his songs. The male of group A went away to his home range after Laki-laki’s approach. These extra-pair duettings suggest the possibility of extra-pair copulation in agile gibbons. More 
longitudinal observations will be necessary to confirm the social dynamics in agile gibbons.

\section{ACKNOWLEDGMENTS}

We thank Professor Hirohisa Hirai for his support. We especially thank Dr. Anas

Salsabila, Dr. Mansyurdin, Dr. Syamsuardi, Dr. Tesri Maideliza, and the rest of the staff at Andalas University for their support in the field station in Sumatra, Indonesia; Dr.

Dondin Sajuthi, Dr. Hery Wijayanto, and the other staff members at the IPB Primate Research Center for their support in Indonesia; Dr. Toshiaki Tanaka for valuable comments; Ms. Yoko Kaneko for helpful assistance in the data analysis; LIPI (Indonesian Institute of Science) for giving us permission to conduct the research; and anonymous reviewer for improving our manuscript. This study was conducted under the Memorandum of Understanding between Primate Research Institute, Kyoto University and Department of Biology, Andalas University. We adhered to the legal requirements of Indonesia. This study was supported by a Grant-in-Aid for overseas research (B) (20405016) to Hirohisa Hirai, and for the Global Centres of Excellence Program (A06) to Kyoto University, MEXT, Japan. 


\section{REFERENCES}

Barelli C, Heistermann M, Boesch C, Reichard UH (2008) Mating patterns and sexual swellings in pair-living and multimale groups of wild white-handed gibbons, Hylobates lar. Animal Behaviour 75:991-1001

Bartlett TQ (2003) Intragroup and intergroup social interactions in white-handed gibbons. International Journal of Primatology 24:239-259

Brockelman WY (2009) Ecology and the social system of gibbons. In: Lappan S, D.J. W (eds) The Gibbons. Springer, pp 211-239

Brockelman WY, Reichard U, Treesucon U, Raemaekers JJ (1998) Dispersal, pair formation and social structure in gibbons (Hylobates lar). Behavioral Ecology and Sociobiology 42:329-339

Farabaugh E (1982) The ecological and social significance of duetting. In: Kroodsma D, Miller E, Ouellet H (eds) Acoustic communication in birds. Academic Press, New York, pp 85-124

Fuentes A (2000) Hylobatid communities: Changing views on pair bonding and social organization in hominoids. In: Yearbook of Physical Anthropology, Vol 43 2000, vol 43, pp 33-60

Geissmann T (2002) Duet-splitting and the evolution of gibbon songs. Biological Review 77:57-76

Groves C (2001) Primate Taxonomy. Smithsonian Institution Press, Washington Haimoff E (1984) Acoustic and organizational features of gibbon song. In: Preuschoft H, Chivers D, Brockelman W, Creel N (eds) The Lesser Apes: Evolutionary and Behavioural Biology. Edinburgh University Press, Edinburgh, pp 333-353

Hooge P, Eichenlaub B (1997) Animal movement extension to arcview. ver. 1.1. In. Alaska Science Center - Biological Science Office, U.S. Geological Survey, Anchorage

Lappan S (2007) Social relationships among males in multimale siamang groups. International Journal of Primatology 28:369-387

Leighton D (1987) Gibbons: Territoriality and monogamy. In: Smuts B, Cheney D, Seyfarth R, Wrangham R, Struhsaker T (eds) Primate Societies, vol 135-145. University of Chicago Press, Chicago

MacKinnon J, MacKinnon K (1977) The formation of a new gibbon group. Primates 18:701-708

Marshall J, Sugardjito J (1986) Gibbon Systematics. In: Comparative Primate Biology, vol I. Alan R. Liss, Inc, pp 137-185

Oyakawa C, Koda H, Sugiura H (2007) Acoustic features contributing to the 
Koda et al. Male replacement and home range stability of agile gibbons/14

individuality of wild agile gibbon (Hylobates agilis agilis) songs. American journal of primatology 69:777-790

Palombit R (1994a) Dynamic pair bonds in hylobatids: implications regarding monogamous social system. Behaviour 128:65-101

Palombit RA (1994b) Extra-pair copulations in a monogamous ape. Animal Behaviour 47:721-723

Palombit RA (1999) Infanticide and the evolution of pair bonds in nonhuman primates. Evolutionary Anthropology Issues News and Reviews 7:117-129

Reichard U (1995) Extra-pair copulations in a monogamous gibbon (Hylobates lar). Ehology 100:99-112

Reichard UH, Barelli C (2008) Life history and reproductive strategies of Khao Yai Hylobates lar: implications for social evolution in apes. International Journal of Primatology 29:823-844

Sommer V, Reichard U (2000) Rethinking monogamy: The gibbon case. In: Kappeler P (ed) Primate Males: Causes and Consequences of Variation in Group Composition. Cambrige University Press, Cambridge

van Schaik CP, Dunbar RIM (1990) The evolution of monogamy in large primates: a new hypothesis and some crucial tests. Behaviour:30-62

White GC, Garrott RA (1990) Home Range Estimation. In: Analysis of Wildlife Radio-Tracking Data. Academic Press, San Diego

Whitten A (1982a) The ecology of singing in Kloss gibbons (Hylobates klossii) on Siberut Island, Indonesia. International Journal of Primatology 3:33-51

Whitten AJ (1982b) Home range use by Kloss gibbons (Hylobates klossii) on Siberut Island, Indonesia. Animal Behaviour 30:182-198 


\section{Figure legend}

\section{Figure 1}

Sound spectrogram of great calls given by Gula, the adult female of group B. Her great calls show the remarkable acoustic features that identified this group. In her great calls, a sudden change of the pitch contour in the introductory part and a hoarse pitch in the maximum frequency were always observed (areas surrounded by the dotted circle and dotted elipse). We were able to use her acoustic cues as her "signature"

\section{Figure 2}

Map of the study area. Dots denote the singing locations of the B group members in 2005, and triangles indicate the singing locations in 2006. The curves represent 50-m contours (range 250-350 m). The polygon outlined with the solid line is the minimum convex polygon (MCP) estimated as the home range in 2005, and the polygon outlined with the dotted line is the range in 2006. The gray shading represents the area of overlap between the two home ranges. Symbols +, center of gravity of the MCP in 2005; X, center of gravity of the MCP in 2006 
Koda et al. Male replacement and home range stability of agile gibbons/16

\section{Figure 1}

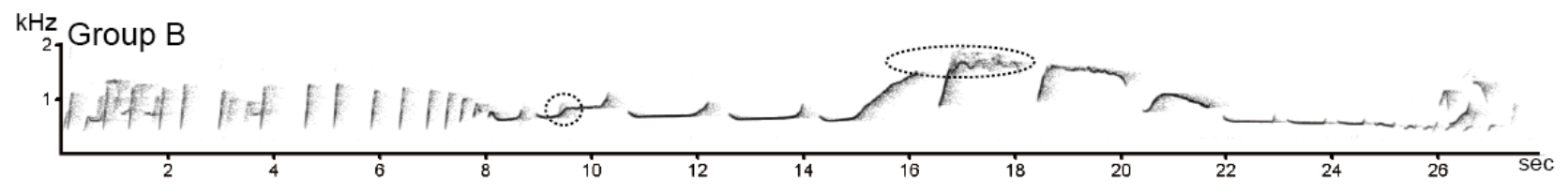


Figure 2

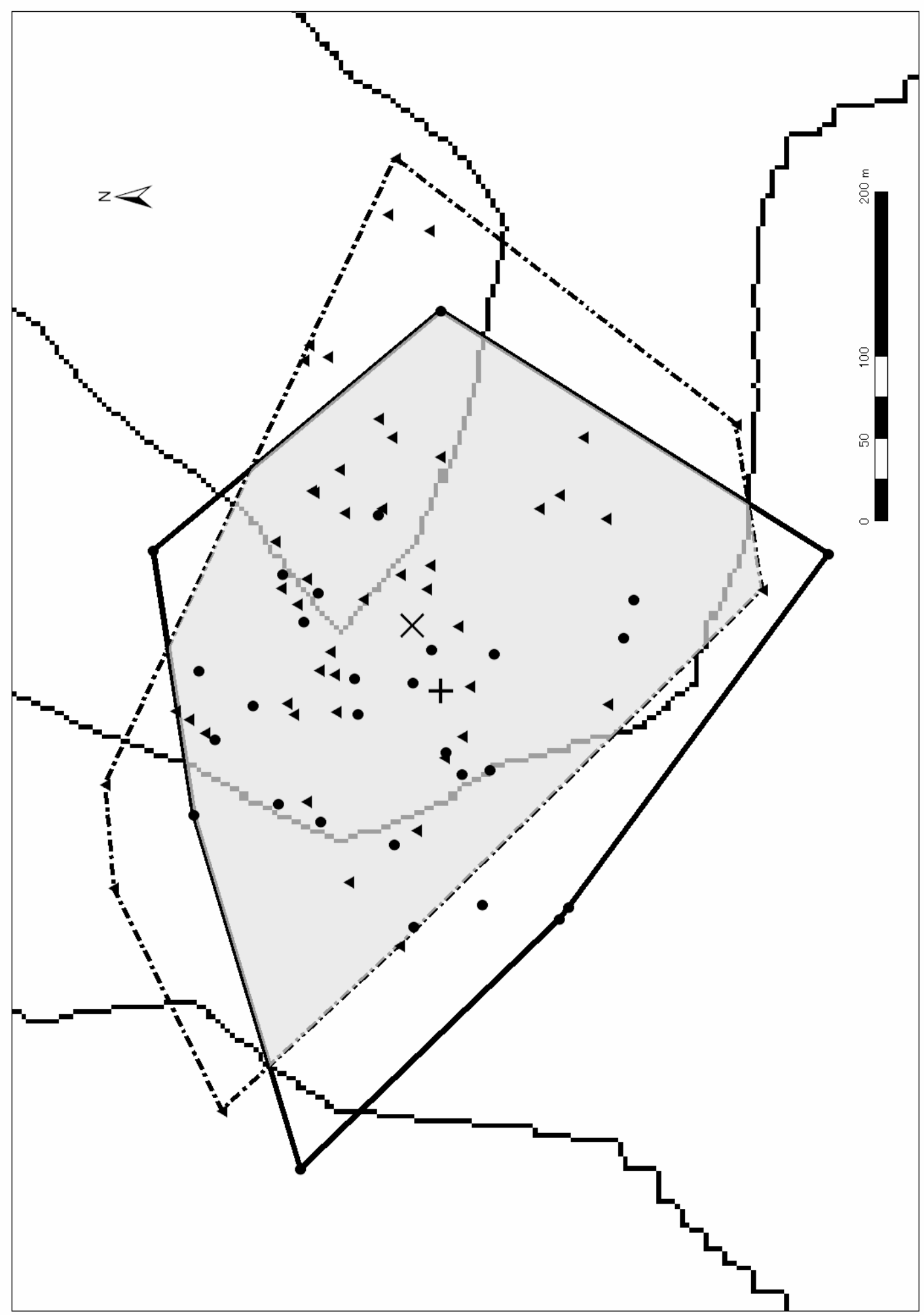

